\title{
La naturaleza viva en las Soledades de Góngora. Uso de la metáfora
}

\author{
Mariapia LAMBERTI \\ Universidad Nacional Autónoma de México
}

El presente artículo tiene como objetivo puntualizar y enriquecer el estudio estilístico que existe alrededor de la obra del poeta Luis de Góngora. La metáfora perteneciente al barroco ha sido estudiada por diversos críticos y en diversos poetas; sin embargo, es bastante claro que el estilo de Góngora supera al de muchos de su época. Así pues, nos dedicamos a explorar en qué consiste dicha excelencia y, de manera más precisa, a analizar de qué forma la metáfora no sólo "traslada imágenes" sino que también vitaliza y atribuye acciones y sentires humanos a la naturaleza que rodea a los protagonistas de lo narrado.

PALABRAS CLAVE: Góngora, barroco, metáfora, naturaleza, humanización.

The aim of this article is to detail and enrich the stylistic study that surrounds the work of the Spanish poet Luis de Góngora. The metaphor of the baroque period has been studied by several literary critics and in the work of different poets, but it is very clear that Gongora's style is superior, in a certain way, to that of his contemporaries. That is why we dedicate this study to examine the characteristics that determine his mastery and, in a more accurate way, to analyze in which way the metaphor not only "transfers images" but also vitalizes and attributes actions and human feelings to the natural environments that surrounds the characters.

KEY WORDS: Góngora, baroque, metaphor, nature, humanization.

En 1927, Federico García Lorca dictó una célebre conferencia en la cual defendía y rescataba la poesía de Luis de Góngora, del denuesto crítico y marginación en el panorama literario de España del que había sido víctima durante tres siglos. Leer hoy aquellas palabra de defensa (García Lorca: 115-144), pensar que hace poco menos de un siglo fueran necesarias, nos suena no sólo sorpresivo sino casi escandaloso. La excelencia y el prestigio poético de Góngora son hoy tan asentados que hemos literalmente olvidado que hubo un tiempo no muy lejano en que se le tildaba de 'oscuro', de 'príncipe de las tinieblas' con la intención de rebajar su calidad creadora y su excelencia formal. Y nos hemos olvidado también que fue a aquella conferencia en el tercer 
centenario de la muerte de Góngora la que cambió radicalmente la perspectiva crítica y abrió no sólo el camino para la formación de una generación poética esplendorosa, de la que Lorca fue el más luminoso exponente, sino también un periodo de estudios sobre las característica del sumo poeta cordobés que se ha enriquecido progresivamente en estos casi cien años.

Pero releer aquel texto sobre "La imagen poética de Luis de Góngora", lírico en su gran parte, hondamente poético, cuajado a su vez de imágenes y metáforas, sigue siendo inspirador, y sigue puntualizando los aspectos básicos de la imagen gongorina que conviene seguir ahondando.

El texto de Lorca es fundamentalmente intuitivo, refleja el encuentro de un poeta con otro poeta, y deja percibir claramente que buena parte de este encuentro místico se queda oculto en el alma del que se atreve a hablar de este encuentro; sin embargo, enfoca los puntos principales del arte imaginifico de Góngora — y nos surge espontáneo aplicarle el adjetivo que siglos después D'Annunzio acuñara para sí mismo-, sobre el que se han explayado los críticos.

Una premisa se hace necesaria. La literatura barroca europea conoce en varias lenguas un fenómeno paralelo: un rebuscamiento lingüístico e imaginativo, la predilección para los temas paganizantes, los ambientes arcádicos, las intertextualidades - si no directamente los préstamos o las paráfrasis - de los clásicos. Esta 'moda' suscitó entusiasmo y polémicas en todas las naciones; derivados del nombre de quien primero la puso en práctica, o creados ingeniosamente, los términos que la indican fueron usados a menudo en forma despreciativa: marinismo en Italia, preciosismo en Francia, eufuismo en Inglaterra, culteranismo en España; digamos que el término gongorismo que ahora usamos comúnmente es reciente, acaso se emplea con respeto desde la reivindicación del poeta y su estilo realizada en 1927, mientras que los otros términos europeos se utilizaron - con su matiz negativo - desde el momento en que se difundió esta escritura metafórica y latinizante en extremo. Por lo que respecta el término 'culteranismo' sabemos que fue una voz despectiva y burlesca, modelada sobre 'luteranismo': para indicar un estilo hereje y desviado, oponiéndolo al conceptismo, la forma del barroquismo poético aceptada y hasta admirada en España, de la que Quevedo fue el máximo exponente. Los estudios sobre el barroco en sus diferentes manifestaciones artísticas se han multiplicado en el siglo XX (nos atrevemos a pensar que después de la revaluación española de los años veintes); y en el ámbito literario la metáfora, como elemento príncipe del estilo barroco, ha tenido siempre espacio prioritario en los análisis.

Los innumerables analistas de Góngora han centrado su atención en su uso de la metáfora, así como los estudiosos del barroco como fenómeno cultural del siglo XVII (y no sólo). Recordamos entre los primeros a Dámaso Alonso, que editó las Soledades (1970 y 1974); Mauricio Molho (1977), y Robert Jammes (1987); en términos generales, la metáfora barroca ha sido estudiada por analistas de muchos países, como el alemán Harald Weinrich (1976), el italiano Giuseppe Conte (1972) y la psicoanalista Julia Kristeva (1985).... Y el juego metafórico sigue intrigando y dando temas de investigación. 
Sin embargo, hoy consideramos que el barroquismo de Góngora supera con mucho la calidad estética de los barrocos europeos. ¿En qué consiste esta excelencia?

García Lorca señala algunos puntos de esta excelencia, pero hace, en términos genéricos, una afirmación que nos desconcierta: "La metáfora está siempre regida por la vista". Y prosigue: "Ningún ciego de nacimiento puede ser un poeta plástico de imágenes objetivas"; "Todas las imágenes se abren, pues, en el campo visual" (123-124).

La lectura de Góngora, sin embargo, nos ofrece un panorama que trasciende estas afirmaciones. Al leer sus poemas - y nos centraremos en las Soledades y en el Polife$m o$, pero podríamos acercarnos a todas sus formas de expresión poética - percibimos una naturaleza viva, que actúa a la par que los personajes humanos que protagonizan la anécdota narrada.

La metáfora gongorina, de hecho, lejos de ser totalmente visual, como pretende Lorca, no traslada únicamente imágenes; no es una 'comparación sin términos comparativos', como se la define normalmente. El verbo gongorino (y el sentido creador de la palabra que empleamos es voluntario) atribuye a los objetos naturales, inanimados, o a los conceptos abstractos, acciones y sentires propiamente humanos.

Consideremos el empleo verbal. El verbo 'besar', por ejemplo, está usado repetidas veces: el náufrago de la primera de las Soledades, recién llegado a la playa, "besa" (v. 29) la arena cuando encuentra "hospitalidad donde halló nido / de Júpiter el ave" (vv. 27-28), y su beso puede haber sido natural. Pero después de este uso que puede describir un gesto real altamente emotivo, encontramos otros: el peregrino, alabando el "bienaventurado albergue", dice:

\author{
Tus umbrales ignora \\ la adulación, Sirena \\ de reales palacios, cuya arena \\ besó ya tanto leño
}

(vv. 24-27)

Aquí encontramos la personificación de la Adulación (prosopopeya clásica, si queremos) y también la del "bienaventurado albergue" al que se dirige nuestro protagonista cuatro veces. Pero es la personificación del "leño", metáfora común para indicar la nave, que nos llama la atención, por su valor abstracto en este caso, y porque "besa" las arenas del palacio de la Adulación. Metáfora compleja en tres niveles. Y asimismo, el anciano ("político serrano / de canas grave", vv. 371-372) que denuesta la osadía humana de haber surcado las ondas del mar, dirigiéndose a la Codicia, dice: "Los reinos de la Aurora al fin besaste" (v. 464). Y contamos otras menciones de este verbo en el sentido de llegar, tocar; es una simple metáfora, es emplear una imagen entrañable — el beso - en lugar de un verbo más frío. 
Pero si leemos unos versos más, en el mismo apóstrofe a la Codicia, que sigue siendo el sujeto que cumple todas las aventuras marítimas lamentadas por el anciano, se le recuerda que

la aromática selva penetraste, que al pájaro de Arabia - cuyo vuelo arco alado es del cielo, no corvo, mas tendidopira le erige, y le construye nido.

(vv. 468-472)

La imagen mítica del ave Fénix, con la metáfora explícita del vuelo ("cuyo vuelo es") que se define como arco iris con alas, aunque arco no curvo, como su término indica, sino contradictoriamente rectilíneo, atrae nuestra atención; pero en la misma frase encontramos la selva aromática personificada, que al pájaro de Arabia "erige" la pira y "construye" el nido, cobrando relevancia en la imagen.

Regresemos al inicio del poema: encontramos en primer término la metáfora mitológica, que se refiere a la constelación de Tauro, presente en el cielo en la "estación florida" (v. 1): un toro raptó a Europa, pero bajo su forma, que por lo tanto era 'mentida', se celaba el dios supremo, Zeus. Y no basta la alusión mitológica; para decir que este toro divino se encuentra en el cielo, se dice que "pace estrellas" (v. 6). Y poco más adelante, cuando el náufrago llega a salvo, cuelga de una roca (como en Roma y en Grecia se usaba hacer en la pared de los templos, en agradecimiento a los dioses, divinizando por ende la roca misma) los restos de su nave:

que aun se dejan las peñas

lisonjear de agradecidas señas.

(vv. 32-33)

La humanización de los elementos naturales es completa, y empezamos a movernos en una naturaleza viva y partícipe. Ya no nos extraña que el vestido mojado del náufrago lo es porque ha "bebido" (v. 35) el océano (no sus aguas: el océano mismo); el joven, este océano bebido

restituir le hace a las arenas;

y al Sol le extiende luego,

que, lamiéndole apenas

su dulce lengua de templado fuego, lento lo embiste, y con suave estilo la menor onda chupa al menor hilo. 
El Sol tiene lengua, lame y chupa el agua del mar del vestido, y lo hace con delicadeza, pues su lengua-rayos es "dulce" y de calor templado.

Pasamos ahora a los adjetivos. Nos quedamos en el primer episodio de las Soledades. La participación activa de los elementos naturales se evidencia desde el primer movimento del poema. El "náufrago y desdeñado sobre ausente" (v. 9)

lagrimosas de amor dulces querellas

da al mar; que condolido,

fue a las ondas, fue al viento

el mísero gemido,

segundo de Arïón dulce instrumento.

(vV. 10-14)

El mar se apiada del peregrino (se duele con él), y lo acompaña en su lamento que aplaca la tempestad como la lira de Arión. Aceptamos como natural entonces que la "breve tabla" (v. 18) que salva al náufrago desdeñado sea un "piadoso miembro roto" (v. 17) de un pino que en su montaña natal siempre fue "opuesto" al "enemigo Noto" (vv. 15-16).

Como hemos notado la repetición del verbo 'besar', podemos mencionar el adjetivo ‘émulo' (uno por cierto de los que enumera Quevedo como estrafalarios y gongoristas en su poema satírico "Quien quisiere ser Góngora en un día /la jeri (aprenderá) gonza siguiente...”). Émulo es del Termodonte el arroyuelo desatado del monte fragoso; émulo también del carro del sol el navío que cruza el estrecho de Magallanes en la alocución a la Codicia:

Zodíaco después fue cristalino

a glorïoso pino,

émulo vago del ardiente coche

del Sol, este elemento,

que cuatro veces había sido ciento

dosel al día y tálamo a la noche,

cuando halló de fugitiva plata

la bisagra, aunque estrecha, abrazadora

de un Océano y otro siempre uno,

o las columnas bese o la escarlata,

tapete de la Aurora.

(vv. 473-483)

El pino (la nave) es glorioso y —voluntaria, conscientemente- quiere ser igual al carro del Sol; el estrecho de mar es bisagra de plata, y es una metáfora por analogía; pero este blancor resplandeciente que sugiere la analogía con la plata se debe a 
la espuma de las olas turbulentas que van y vienen, y he aquí que a la plata se le acopla el adjetivo fugitiva, adjetivo que implica acción consciente, que humaniza. A su vez, la bisagra abraza las dos partes del Océano que siempre son uno, sea que bese las columnas de Hércules en Occidente, o el color púrpura que en las lejanías del Este

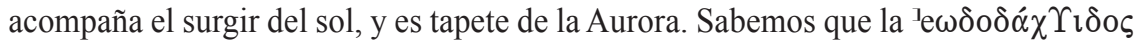
$\tilde{\varepsilon} \omega s$ es una diosa, pero aquí concretamente pisa púrpura como una reina, púrpura que se besa en signo de sujeción. Encontramos otra vez el verbo 'besar', pero aquí, cerca del adjetivo derivado de 'abrazar', cobra todo su significado sutilmente erótico. Pero este verbo sugiere también una entrega, un abandono, un sometimiento. Veamos la alocución inicial al Duque:

$y$, en cuanto da el solícito montero, al duro robre, al pino levantado

-émulos vividores de las peñaslas formidables señas del oso que aun besaba, atravesado, la asta de tu luciente jabalina

("Dedicatoria", vv. 16-21)

En esta "Dedicatoria" encontramos por primera vez el adjetivo 'émulo', ahora referido a los árboles más majestuosos, cuya altura, comparable, hiperbólicamente, a la de los peñascos, se define como una competición, sugiriendo así una voluntad consciente; y el 'beso' que el oso traspasado a muerte da al arma mortífera, es señal inequívoca de sometimiento total a la grandeza dominante del Duque.

La "Dedicatoria" de las Soledades nos remite a la del Polifemo: en la narración mitológica, cuya lectura no presenta eventos desconocidos para el lector, la intención se centra en el modo en que se trata la anécdota; y también aquí, en el Polifemo, el lector se mueve en una naturaleza viva, que siente y actúa a la par que los protagonistas. Sobre ésta se agrega, solamente, el hermoseamiento visual, el preciosismo y la preciosidad. En las dos primeras octavas del Polifemo:

Éstas que me dictó, rimas sonoras, culta sí aunque bucólica Talía, oh excelso Conde, en las purpúreas horas que es rosas la alba y rosicler el día, ahora que de luz tu niebla doras, escucha, al son de la zampoña mía, si ya los muros no te ven de Huelva peinar el viento, fatigar la selva. 
Templado pula en la maestra mano

el generoso pájaro su pluma,

o tan mudo en la alcándara, que en vano

aun desmentir el cascabel presuma;

tascando haga el freno de oro cano

del caballo andaluz la ociosa espuma;

gima el lebrel en el cordón de seda,

y al cuerno al fin la cítara suceda.

(vv. 1-16)

Encontramos el verbo 'dorar', muy caro a Góngora; es el "excelso Conde” (v. 3) que con su luz ilustra y ensalza la Niebla de su apellido; si eso puede interpretarse como un hablar figurado pero pertinente, he aquí que acto seguido encontramos los muros de Huelva que ven al conde "peinar el viento y fatigar la selva" (v. 8), donde 'peinar' y 'fatigar' agregan metáfora a metáfora, dando cuerpo a lo impalpable del viento y sensibilidad a lo estático de la selva. En la segunda estrofa, el pájaro "generoso" (v. 10; adjetivo que indica fiera nobleza, pero atribuible más a un ser autoconsciente que a un bruto) pule sus plumas sobre la mano del maestro cetrero; pero en los versos inmediatamente siguientes, presume desmentir (v. 12) el cascabel que lleva colgado, con su inmovilidad y silencio. Dos verbos que nos remiten a una actitud y relación social muy humana. Y el atrevimiento va más allá: es la espuma ociosa del caballo andaluz que vuelve blanco (pero el poeta dice cano) el freno con el mascar que éste hace. El verbo al gerundio (tascando, v. 13) no puede referirse semánticamente sino al caballo, y deshaciendo la enálage, también lo ocioso (v. 14) se refiere propiamente al caballo, pero éste no aparece sino como un genitivo de especificación de lo que hace la función de sujeto del verbo, que es la saliva espumosa - a la que se refiere el adjetivo, y sintácticamente también el gerundio, a menos que le adjudiquemos un forzado sentido adjetival y consideremos su colocación como extremadamente hiperbática- que él mismo produce: el Uroboros se muerde la cola, la frase gira sobre sí misma concluyendo el vórtice de sentido que rompe toda percepción previa de la realidad.

En este punto no nos extraña ya que el espumoso mar siciliano argente los pies del cabo Lilibeo con el baño de plata de sus rompientes (vv. 25-26), ni que la "infame turba de nocturnas aves" nos enseñe que el caliginoso lecho de la gruta sea el seno oscuro de la noche (vv. 37-39).

Regresemos a Lorca. El aspecto visual de muchas metáforas gongorinas es innegable: colores y comparaciones implícitas o explícitas con los elementos más resplandecientes de la naturaleza nos vienen al encuentro a cada instante: hemos visto en las dos primeras octavas del Polifemo "las purpúreas horas / Que es rosas la alba y rosicler el día" (vv. 3-4). Pero el elemento más espléndido e inquietante es esta vitalización constante; en ella se insertan los juegos etimológicos, tan caros a los poetas barrocos, que cobran en este contexto un peculiar sentido. Cuando el peregrino de las Soledades 
contempla el paisaje campestre desde el alto del risco, ve el luciente río, hijo de los montes (v. 299), que "tiraniza los campos útilmente" (v. 101; otro verbo voluntario) "con torcido discurso, aunque prolijo" (v. 100). Sabemos que a la latina discurso significa recorrido, pero la anfibología con el sentido común que se remite a la palabra humana, se presenta de inmediato, y se refuerza con el adjetivo prolijo.

Es un mundo creado, un mundo nacido de un verbo, como dijimos al inicio, un mundo alternativo y esplendido, que no necesita ser vitalizado, como en época clásica, con la presencia de entidades divinas que habiten los elementos naturales, pues éstos viven de vida propia. Y los verbos y adjetivos que dan vida y sentir a los elementos de la naturaleza los podemos rastrear en toda la obra gongorina.

Con otras palabras y otro enfoque dice Eunice Joiner Gates, en su The Metaphors of Luis de Góngora, de la metáfora gongorina: "un examen de las metáforas del conjunto de la poesía de Góngora [...] muestra que, mientras en conjunto el número derivado de los fenómenos de la naturaleza es grande, es relativamente pequeño si se comparan con las metáforas relacionadas con las influencias y características humanas" (Orozco Díaz: 89).

No percibimos inicialmente estas características, estos verbos y adjetivos peculiares y su efecto, deslumbrados por la complejidad y el atrevimiento metafórico: pero son los que dan esta sensación inigualable que se experimenta al acercarnos a la poesía de este máximo poeta. "Góngora no crea sus imágenes sobre la misma Naturaleza, sino que lleva el objeto, cosa o acto a la cámara oscura de su cerebro y de allí salen transformados para dar el gran salto sobre el otro mundo con que se funden".

Son palabras de Lorca (1962: 130), que, más allá de lo visual que postula hablando de la metáfora en cuanto tal, percibe esta recreación profunda, aun sin concretizarla en detalles técnicos. Quien se sumerge en la palabra de Góngora, vive la experiencia de un mundo alternativo, donde todos los elementos, llevados al vértice de su posible belleza, rodean al hombre con emociones y sentimientos que acompañan y emulan (para usar una palabra cara a Góngora) el mundo humano. Con él, con el infinito poeta granadino, podemos concluir que Góngora, en su vida, no conoció el triunfo que sus versos inigualables le debían de merecer: "Intuye con claridad que la naturaleza que salió de las manos de Dios no es la naturaleza que debe vivir en los poemas" (131).

\section{Obras citadas}

ALonso, Damaso. 1974. Góngora y el "Polifemo". Madrid: Gredos. 1970. Estudios y ensayos gongorinos. Madrid: Gredos.

CONTE, Giuseppe. 1972. La metafora barocca. Saggio sulle poetiche del Seicento. Milán: Mursia.

GARCíA LORCA, Federico. 1962 [1942]. "La imagen poética de Luis de Góngora". Obras completas. Ed. G. de TORRE. Buenos Aires: Losada. Pp. 115-144. 
GóngORA, Luis de. 1982. [Revista de Occidente, 1927]. Soledades. Ed. D. AlonSo. Madrid: Alianza Editorial.

JAMMES, Robert. 1987. La obra poética de don Luis de Góngora y Argote. Madrid: Castalia.

KRISTEVA, Julia et al. 1985. [El] trabajo de la metáfora. Identificación/Interpretación. Trad. Margarita MizRAJI. Barcelona: Gedisa.

Molho, Maurice. 1977. Semántica y poética (Góngora, Quevedo). Barcelona: Grijalbo.

Orozco DíAz, Emilio. 1984. Introducción a Góngora. Barcelona: Crítica.

WIENRICH, Harold. 1976. Metafora e menzogna. Trad. L. RITTER SANTINI. Bolonia: Il Mulino. 